\title{
O OLHAR DA BIOÉTICA DE INTERVENÇÃO NOS DIREITOS INERENTES AO IDOSO E A INFLUÊNCIA DA TEORIA DA RESERVA DO POSSÍVEL ${ }^{1}$
}

\author{
Tami Cristina Maboni ${ }^{2}$ \\ Patrícia Spagnolo Parise ${ }^{3}$
}

\begin{abstract}
RESUMO: A população idosa já ocupa um lugar significativo no cenário populacional atual e isso demanda uma atenção especial por parte dos estudiosos dos direitos humanos. Sendo assim, o presente artigo tem por escopo analisar os direitos sociais do idoso vistos pelo ângulo da bioética de intervenção. Esta atua não somente em conflitos de valores, mas também abarca questões materiais e subjetivas com a finalidade de trazer o equilíbrio e a harmonia universal. A implementação de muitas propostas de atenção ao idoso favorece o acesso à informação e à prestação de serviço sócio-assistencial, fortalecendo, assim, sua condição de ser cidadão. Para tanto, desenvolveu-se uma pesquisa de natureza exploratória, documental indireta e bibliográfica baseada nos escritos de estudiosos do Direito e nas disposições constantes no ordenamento jurídico brasileiro.
\end{abstract}

PALAVRAS-CHAVE: Bioética de intervenção, idoso, políticas públicas, reserva do possível.

\section{The look of intervention bioethics in the rights attached to the elderly and the influence of the theory of reservation's possible.}

\begin{abstract}
The elderly population already occupies a significant place in the current population scenario and one that demands special attention by scholars of human rights. Thus, the scope of this paper is to analyze the social rights of the elderly seen by the angle of the intervention bioethics. This works not only in conflicts of values, but also includes material and subjective questions, in order to bring balance and universal harmony. Implementation of many proposals for geriatric care promotes access to information, the provision of social assistance services, strengthening its status as a citizen. To this end, we developed an exploratory survey, documentary and bibliographical indirect, based on the writings of scholars of law and the provisions of the Brazilian legal system.
\end{abstract}

KEY-WORDS: Intervention bioethics, elderly, public policy, reserve possible.

\section{INTRODUÇÃO}

\footnotetext{
${ }^{1}$ Este artigo resulta do projeto de pesquisa "Bioética e inclusão social", vinculado à Universidade de Rio Verde-FESURV e coordenado pela Professora Mestre Patrícia Spagnolo Parise.

${ }^{2}$ Aluna de graduação do Curso de Direito, Universidade de Rio Verde - FESURV. E-mail: tamimaboni@hotmail.com.

${ }_{3}^{3}$ Orientadora, Professora Mestre da Faculdade de Direito, Universidade de Rio Verde - FESURV. E-mail: ps.parise@hotmail.com.
} 
O corte etário adotado pela Organização das Nações Unidas para determinar a população idosa nos países desenvolvidos é de 65 anos. Já nos países em desenvolvimento, onde a expectativa média de vida é menor, considera-se a idade de 60 anos como sendo de transição para o segmento idoso da população (IBGE, 2011).

Segundo o censo do Instituto Brasileiro de Geografia e Estatística (IBGE) de 2010, no Brasil, existem mais idosos do que crianças de 0 a 4 anos, sendo que as regiões sul e sudeste foram as que apresentaram os maiores índices de idosos. A taxa da população que se enquadra no grupo de crianças de 0 a 4 anos é de $7,3 \%$, sendo $3,7 \%$ para o sexo masculino e 3,6\% para o sexo feminino. Já o percentual de idosos entre 60 e 85 anos na população é de $10,8 \%$.

O devido respeito ao idoso pode ser considerado o mandamento da vida moderna. O idoso, como constituinte da sociedade contemporânea, exige cuidados de ordem corporal, psicológica e social, que proporcionem bem estar a essa classe da população. No entanto, percebe-se a existência de uma falta de comprometimento social frente à condição de ser idoso, no que se refere ao atendimento das necessidades que lhe são vitais.

Saber das necessidades dos idosos e ter consciência de tais necessidades para poder atendê-las quando necessário é fundamental para o bem estar social universal. Ao contrário do que muitas pessoas acreditam, os idosos não são pessoas improdutivas à espera da morte, mas são parte integrante do mundo contemporâneo e tendem a permanecer como agentes participantes de todo o processo dinâmico da vida em sociedade.

Quando se trata de direitos sociais, torna-se interessante utilizar um importante instrumento, que auxilia na compreensão e na identificação de problemas e necessidades pertinentes que insistem em permear o cotidiano da população brasileira: a bioética de intervenção. A bioética tem como objeto de estudo a conduta humana no âmbito das ciências da vida e da saúde, sendo que o faz sob a ótica dos valores e princípios morais.

Em face da problemática concernente à concretude dos direitos do idoso, este artigo procurou focar três pontos principais: 1) uma análise da bioética nos problemas e necessidades cotidianos da população brasileira idosa; 2) a discussão acerca da efetivação dos direitos e garantias do idoso através das políticas públicas e 3) os limites e barreiras que impedem a real implementação das políticas públicas. 
Diante disso, pretende-se refletir sobre a inclusão social do idoso, atentando para as necessidades cotidianas que permeiam a vivência e a sobrevivência dessa classe populacional. Assim, o presente artigo tem por objetivo contribuir para uma conscientização humanitária, ética e comprometida tendo em vista o contexto histórico, social e cultural em que se insere a população idosa e não apenas se preocupando com as questões morais e éticas. Intenta-se também trazer para a discussão, o dilema enfrentado pelo legislador na tomada de decisão orçamentária e as inevitáveis consequências sofridas pelo idoso provenientes de tal decisão.

\section{BIOÉTICA DE INTERVENÇÃO E INCLUSÃO SOCIAL DO IDOSO}

Começou-se a falar em bioética a partir dos anos 70, nos Estados Unidos e Europa, com uma abordagem relativa às questões sobre vida e morte. Os primeiros conceitos de bioética foram apresentados ao mundo pelo oncologista estadunidense Van Rensselder Potter. A área foi conceituada por ele como uma disciplina que recorreria às ciências biológicas para melhorar a qualidade de vida do ser humano, permitindo ao homem participar da evolução biológica e preservando, assim, a harmonia universal (DINIZ, 2002, p. 9). Esses conceitos, trazidos por Potter, estavam mais ligados à ecologia e aos avanços biotecnológicos, sem demonstrar maiores preocupações quanto aos problemas éticos e morais enfrentados pelas pessoas no cotidiano.

Alguns anos depois, em 1979, Tom Beauchamp e James Childress publicaram o livro Principles of Biomedical Ethics, que tinha como fundamento os quatro princípios tradicionais da bioética: autonomia, beneficência, não maleficência e justiça. Assim como outros pesquisadores estadunidenses, Beauchamp e Childress conduziram seus estudos a partir desses quatro princípios, pautando a bioética no que se denominou de "principialismo". Tais teóricos acreditavam que o principialismo seria um instrumento acessível e prático para a análise dos conflitos surgidos no campo bioético (GARRAFA, 2005, p. 4).

Além desses princípios tradicionais, existem outras categorias ou referenciais, como a responsabilidade, a libertação, a tolerância e a solidariedade e também o que Garrafa designa de "quatro pês": a prudência, a precaução, a proteção e a prevenção. Há ainda outros princípios que devem ser constantemente reavaliados e reinterpretados no intuito de formular normas mais ampliadas (GARRAFA, 2005, p. 4).

Para Gamboa-Bernal (2009, p. 175): 
$Y$ aunque es indudable que estos princípios contienen elementos válidos, su mutua articulación no guarda la coherencia antropológica que es necesaria cuando de personas se habla, y no aclaran qué se debe entender, por ejemplo, por el bien de la persona y por la autonomía del individuo. Además, tales principios son interpretados a la luz de dos teorías que poco pueden tener de coincidentes: el utilitarismo y la deontología. El principialismo carece de una antropología fundante; los principios sostenidos por él están indeterminados y esto lleva necesariamente al relativismo ético; no hay una jerarquia entre los cuatro princípios. ${ }^{4}$

Berlinguer (1993, s/p. apud GARRAFA, 2005, p. 5) traz um conceito mais atual de bioética:

A procura de um comportamento responsável de parte daquelas pessoas que devem decidir tipos de tratamento e de pesquisa com relação à humanidade. Tendo descartado em nome da objetividade qualquer forma de subjetividade, sentimentos ou fundamentos da bioética. Além da honestidade, do rigor científico ou da procura da verdade - pré-requisitos de uma boa formação científica - a reflexão bioética pressupõe algumas questões humanas que não estão incluídas nos currículos universitários.

De uma forma mais objetiva, Kottow (1995, p. 53 apud DOLL \& PY, 2011, p. 293), conceitua bioética como o "conjunto de conceitos, argumentos e normas que valorizam e legitimam eticamente os atos humanos, que podem ter efeitos irreversíveis sobre fenômenos vitais".

Faz-se necessário lembrar o momento em que a bioética se politizou internacionalmente com a homologação da Declaração Universal de Bioética e Direitos Humanos, que ocorreu na $33^{\circ}$ Conferência Geral da UNESCO, em 19 de outubro de 2005 em Paris. Na conferência em questão foram abordadas, além de temas habituais já contemplados pelos principialistas, questões sanitárias, sociais e ambientais, de grande

\footnotetext{
${ }^{4} \mathrm{E}$, embora seja claro que estes princípios contêm elementos válidos, sua mútua articulação não salva a coerência antropológica que é necessária quando se fala de pessoas, e não esclarecem que se deve entender, por exemplo, pelo bem da pessoa e pela autonomia do individuo. Além disso, tais princípios são interpretados sob a luz de duas teorias que podem ter muito pouco em comum: o utilitarismo e a deontologia. O principialismo necessita de uma antropologia fundamental; os princípios suscitados por ele estão indeterminados e isto leva necessariamente ao relativismo ético; não há uma hierarquia entre os quatro princípios. (tradução nossa)
} 
interesse para as nações pobres e/ou em desenvolvimento (GONÇALVES, 2010, p. 227).

Evelise Ribeiro Gonçalves (2010, p. 227) analisa o posicionamento da Declaração como o resgate do sentido atribuído por Van Rensselaer Potter, de uma ética que se relacionava com os fenômenos da vida humana no seu mais amplo sentido, incorporando não somente as questões biomédicas, mas principalmente as ambientais, ligadas à sustentabilidade do planeta.

Garrafa (2005, p. 5) corrobora essa ideia ao afirmar que "o atual conceito de bioética num sentido amplo abrange não somente as ciências médicas e da saúde, mas deve ser encarada de forma multi-inter-transdisciplinar buscando amparo na filosofia, no direito, na teologia, na antropologia, na ciência política, na sociologia, na comunicação, na economia”.

A ampliação teórica no campo da bioética foi muito bem desenvolvida por Giovanni Berlinguer, numa conferência realizada em Roma, no Instituto Gramsci, em março de 1988. Berlinguer foi o primeiro a tratar da distinção entre a bioética de situações persistentes (bioética cotidiana) e a bioética de situações emergentes (bioética de limites ou de fronteira) (GARRAFA, 2001, p. 37).

A bioética de situações emergentes trata de temas atuais, que surgiram a menos de 30 ou 40 anos, relacionados aos avanços biotecnológicos. Abordam-se, assim, questões relacionadas a diversos campos, tais como: engenharia genética, doações e transplantes de órgãos, saúde reprodutiva, eugenia, clonagem, mães de aluguel e biossegurança.

A bioética de situações persistentes detém suas atenções em problemas cotidianos, relacionados ao comportamento e às ideias de cada pessoa. Esse segmento ocupa-se de questões que estão presentes na sociedade desde a Antiguidade; temas que dizem respeito a pontos como exclusão social, discriminações de gênero, raça e sexualidade, democracia, aborto e eutanásia (GARRAFA, 2005, p. 9).

Neste artigo, volta-se para a bioética de situações persistentes, ou também chamada de bioética de intervenção, que trata da inclusão social de grupos marginalizados, em que se inserem os direitos sociais relativos aos idosos.

A bioética de intervenção surge como uma nova proposta teórica na busca de uma aliança concreta com o lado historicamente mais frágil da sociedade. Inclui, assim, a reanálise de diferentes dilemas, tais como autonomia versus justiça/equidade benefícios individuais versus benefícios coletivos individualismo versus solidariedade 
omissão versus participação e mudanças superficiais e temporárias versus transformações concretas e permanentes (GARRAFA \& PORTO, 2003, p. 17).

\subsection{Políticas Públicas, Discricionariedade e Orçamento}

A Constituição de 1988 estabelece, nos artigos 229 e 230, a obrigatoriedade de incluir na agenda política as necessidades e os direitos da população idosa e o Estatuto do Idoso, que determina os direitos e o estabelecimento da rede de proteção e atendimento direcionados aos idosos (BRASIL, 2010, p. 61).

Nesse sentido, o advento do Estatuto do Idoso representa uma mudança de paradigma, já que amplia o sistema de proteção a essa camada da sociedade, caracterizando verdadeira ação afirmativa em prol da efetivação da igualdade. Torna-se necessária a conscientização da população, no que se refere ao respeito dos direitos, da dignidade e da sabedoria de vida desta camada tão vulnerável e, por vezes, desprezada na sociedade.

Faz-se interessante aqui apresentar a legislação específica a essa faixa etária: a Política Nacional do Idoso, Lei 8842/94, a Política Nacional de Saúde do Idoso, Portaria 2528 de 19 de outubro de 2006 e o Estatuto do Idoso, Lei 10.741/2003. Este conjunto de leis possibilita reconhecer o lugar social do idoso, bem como identificar o significado da condição de cidadania desse segmento populacional. Esse modo de entender as condições de vida da população idosa associa-se a um entendimento de cidadania, reconhecendo nisso um exercício e contribuindo, assim, na formação de sujeitos sociais ativos (BRUNO, 2003, p. 75).

O envelhecimento é um direito personalíssimo e sua proteção, um direito social, sendo obrigação do Estado garantir à pessoa idosa a proteção à vida e à saúde, mediante a efetivação de políticas sociais públicas que permitam um envelhecimento saudável e em condições dignas (LENZA, 2010, p. 965). Cabe, dessa forma, às políticas públicas a concretização e efetivação dos direitos e garantias assegurados aos idosos em tais legislações.

A Constituição Federal de 1988 apresenta um modelo de proteção ao idoso quando trata da seguridade social ${ }^{5}$, que envolve os direitos relativos à saúde, à

\footnotetext{
${ }^{5}$ Cf. Titulo VIII, Capítulo II da Constituição Federal de 1988.
} 
previdência e à assistência social. É importante ressaltar que a assistência social é, aqui, entendida como direito e não como filantropia (GOMES, 2009, p. 13).

Busca-se, então, articular os direitos contributivos e as transferências de renda não contributivas vinculadas à assistência social sob a égide dos direitos sociais. Assim, a assistência social integra o sistema de seguridade social como política pública não contributiva, pois visa garantir a proteção social de todos os que dela necessitam e não apenas daqueles que contribuem (GOMES, 2009, p. 13).

A assistência social foi reconhecida como política pública de seguridade social em 1993, com a promulgação da Lei Orgânica da Assistência Social. A partir disso, vários outros marcos legais surgiram, como a Lei Orgânica da Assistência Social (LOAS) ${ }^{6}$, a Política Nacional de Assistência Social (PNAS) ${ }^{7}$, a Norma Operacional Básica do Sistema Único de Assistência Social (NOB-Suas) ${ }^{8}$ e a Norma Operacional Básica de Recursos Humanos (NOB-RH) ${ }^{9}$.

A PNAS garante à pessoa idosa e a sua família o acesso a programas, serviços, projetos e benefícios que contribuam para a efetivação de seus direitos. Estes são organizados pelo Sistema Único de Assistência Social $\left(\mathrm{SUAS}^{10}\right)$, que estabelece regras Norma Operacional Básica do Sistema Único de Assistência Social (NOB-Suas) e Norma Operacional Básica de Recursos Humanos (NOB-RH) - que disciplinam o funcionamento do novo modelo de gestão (GOMES, 2009, p. 19).

Para Maria Paula Dallari Bucci, políticas públicas são programas de ação governamental que visam coordenar os meios à disposição do Estado e as atividades privadas para a realização de objetivos socialmente relevantes e politicamente determinados (BUCCI, 2006, p.241). Assim, esclarece Leonardo Augusto Gonçalves (2009, p. 2):

As políticas públicas são os meios de planejamento para a execução dos serviços públicos. Em todas as áreas o Estado deve possuir políticas públicas de forma clara e precisa na busca de melhor desempenho de suas atividades estatais. As principais políticas públicas são: política econômica, política

\footnotetext{
${ }^{6}$ Cf. Lei Federal no 8.742 de 7 de dezembro de 1993.

${ }^{7}$ Cf. Resolução CNAS no 145, Brasília, novembro de 2004.

${ }^{8}$ Cf. Resolução CNAS no 130, Brasília, julho de 2005, disciplina a gestão da Política de Assistência Social no território brasileiro.

${ }^{9}$ Cf. Resolução CNAS no 1, Brasília, janeiro de 2007, que disciplina a gestão do trabalho da Política de Assistência Social.

${ }_{10}$ Criado pela Lei Orgânica da Assistência Social (LOAS) e teve sua implementação consolidada por meio da Norma Operacional Básica SUAS (NOB-SUAS).
} 
educacional, política habitacional, política ambiental, política previdenciária, política de saúde e política de segurança pública. A fixação das políticas públicas ocorre por meio dos mecanismos estatais de planejamento das ações, estratégias e metas para atingir a finalidade pública de forma eficiente, na prestação de ações e serviços públicos. As políticas públicas correspondem ao planejamento e as obras e serviços públicos caracterizam a execução material da função.

A partir do conceito de políticas públicas, destacam-se algumas necessidades que o idoso brasileiro tem em seu cotidiano e que merecem atenção e empenho do Poder Executivo. Tais necessidades estão relacionadas à saúde física e mental, como locomoção, moradia, lazer, cultura e informação.

A busca por espaços físicos acessíveis, por ser indispensável para adaptação de qualquer indivíduo, ainda que este apresente alguma perda funcional, consiste em uma das necessidades referidas acima, sendo que os ambientes que facilitam a locomoção e permanência dos idosos são designados por estudiosos do ramo como ambientes favoráveis e amigáveis. Os "ambientes amigáveis são aqueles capazes de se ajustar as competências e preferências dos idosos, dando a estes um senso de controle, de autoeficácia e de pertinência" (PRADO \& PERRACINI, 2007, p. 222). Já os ambientes favoráveis traduzem-se em desenhos arquitetônicos que privilegiam a funcionalidade, que, por sua vez, é definida como um termo guarda-chuva para as funções e estruturas do corpo, as atividades e a participação social (OMS, 2003).

Para Guimarães (1999, s/p.),

Um ambiente com acessibilidade atende, diferentemente, uma variedade de necessidades dos usuários, tornando possível uma maior autonomia e independência. Entendendo autonomia, aí, como a capacidade do indivíduo de desfrutar dos espaços e elementos espontaneamente, segundo sua vontade. E independência como a capacidade de se usufruir os ambientes, sem precisar de ajuda.

Transformar ambientes urbanos, como ruas, calçadas, passarelas, meios de transporte e até mesmo seus próprios lares em ambientes acessíveis significa melhorar a 
funcionalidade do idoso e reduzir a incapacidade diante de tarefas simples e corriqueiras. Realizar mudanças nesses meios faz com que o idoso se sinta mais independente e satisfeito consigo mesmo. Além de diminuir estados caracterizados por apatia, desinteresse, ansiedade, reclamações sobre dores e doenças, sentimentos de solidão, depressão, tristeza e inutilidade.

Apesar de muitas mudanças que tem ocorrido em relação ao urbanismo e ao trânsito de veículos e pedestres, ainda verifica-se que a maior parte das cidades não apresenta condições adequadas de livre locomoção para idosos ou deficientes físicos. As calçadas, por exemplo, quando existem, são estreitas e, por vezes, ocupadas por mesas de bares e lanchonetes, entulhos de lixo, materiais destinados a construções, bancas de revistas, entre outros. Há casos ainda em que possuem irregularidades, saliências e crateras, impossibilitando seu uso e fazendo com que estes precisem se deslocar para as ruas, o que aumenta o risco de acidentes.

Conforme destacam Camarano, Kanso, Leitão e Mello (2002), no Brasil, é crescente o número de idosos que mora sozinho ou que passa a maior parte do dia sem nenhuma companhia em casa. Isso é preocupante, uma vez que os ambientes domésticos também apresentam fatores de risco, tais como escadas, pisos escorregadios, objetos guardados em lugares altos demais ou lugares que exigem que se abaixem para pegálos.

A partir disso, medidas simples como rebaixamento das calçadas próximo aos cruzamentos, elevação da faixa de pedestres, presença de corrimãos nas escadas e eliminação dos obstáculos e desníveis nas vias de passeio podem melhorar significativamente a locomoção e a acessibilidade dos idosos. Outra providência que pode ser tomada é a troca de calçadas estreitas e precárias por áreas de convivência calçadas largas com algumas árvores que proporcionem sombra, com bancos e canteiros. Isso cria uma oportunidade de convívio e interação entre as pessoas, além de facilitar a passagem dos transeuntes.

No tocante aos meios de transporte, o decreto 5296/04 estabelece que os transportes coletivos, além das poltronas reservadas aos idosos, devem possibilitar o embarque e desembarque numa área especial, sem as barreiras que os degraus representam.

Esses são apenas alguns dos diversos problemas que os idosos enfrentam diariamente e que demandam ações efetivas para melhorar o convívio e proporcionar qualidade de vida a estes. Tratar do tema inclusão social significa despertar a discussão 
para a criação de novos mecanismos e condições que permitam que as pessoas se sintam realmente incluídas em seu meio social.

Como já discutido anteriormente, as políticas públicas consistem em uma das formas de efetivação da inclusão social. Desse modo, as decisões de onde e como gastar seu orçamento ficam a cargo do legislador. Conforme pondera Canotilho (1982, p. 369), "ao legislador compete, dentro das reservas orçamentárias, dos planos econômicos e financeiros, das condições sociais e econômicas do país, garantir as prestações integradoras dos direitos sociais, económicos e culturais." No momento de colocar em ação os planos e planejamentos, o legislador tem sua liberdade condicionada aos poderes vinculado e discricionário, não sendo, no entanto, uma classificação absoluta para a doutrina, e podendo a Administração Pública manifestar competência discricionária em certos atos e atuar de forma vinculada em outros.

Como explica Fernanda Marinela (2010, p. 188), “o poder vinculado é aquele em que o administrador não tem liberdade de escolha; não há espaço para a realização de um juízo de valor, e, por conseguinte, não há análise de conveniência e oportunidade. Preenchidos os requisitos legais, o administrador é obrigado a praticar o ato".

Ainda segundo Marinela (2010, p.188):

No poder discricionário, o administrador também está subordinado à lei, diferenciando-se do Poder Vinculado, porque o agente tem liberdade para atuar de acordo com um juízo de conveniência e oportunidade, de tal forma que, havendo duas alternativas, o administrador poderá optar por uma delas, escolhendo a que, em seu entendimento, preserve melhor o interesse público.

Um instrumento considerado importante pela Constituição Federal ${ }^{11}$ é o orçamento utilizado no momento de concretizar as políticas públicas, já que dele depende a concretização dos direitos fundamentais. A decisão de gastar é, fundamentalmente, uma decisão política. O administrador elabora um plano de ação, descreve-o no orçamento, aponta os meios disponíveis para seu entendimento e efetua o gasto (OLIVEIRA, 2006, p. 243). Uma vez que o orçamento público foi considerado como um importante instrumento para o desenvolvimento econômico, social e político, a Constituição estabeleceu três leis que se sucedem e se complementam: a Lei do Plano

\footnotetext{
${ }^{11}$ Cf. art. 165 da Constituição Federal de 1988.
} 
Plurianual $(P P A)^{12}$, a Lei de Diretrizes Orçamentárias $(L D O)^{13}$ e a Lei Orçamentária Anual (LOA) ${ }^{14}$. Nos termos do art. $165, \S 4^{\circ}$ e art. $166, \S 4^{\circ}$ da Constituição Federal, tais legislações e os planos e programas governamentais devem caminhar em harmonia (MÂNICA, 2007, p. 3).

\subsection{Teoria da Reserva do Possível e os limites à implementação das Políticas} Públicas

A fim de atender às necessidades mais basilares dos idosos, foram criadas diretrizes instrumentalizadas através da Constituição e de legislações esparsas. A Política Nacional do Idoso (Lei 8842/94), a Política Nacional de Saúde do Idoso (Portaria 2528 de 19 de outubro de 2006) e o Estatuto do Idoso (Lei 10.741/2003) objetivam, em uníssono, proporcionar atenção integral e integrada à pessoa idosa, estruturada de modo a focar direitos, necessidades, preferências e habilidades.

A efetivação das normas constitucionais e das leis esparsas, feita através das políticas públicas, por se tratar basicamente de normas de direito público, exige o dispêndio de recursos financeiros e a observância do orçamento público. Para Bucci (2011, s/p), “as políticas públicas atuam de forma complementar a legislação, cuja característica é a generalidade e abstração, como meio de rematá-la e de concretizar seus princípios e regras, perseguindo objetivos certos e determinados". Como já tratado no tópico anterior, a implementação e concretização das políticas públicas demandam gastos, sendo que fica a cargo do legislador decidir como fazer a aplicação adequada dos recursos financeiros.

Aponta Krell um dos fatores que dificulta a efetividade dos programas e planos públicos:

A eficácia social reduzida dos Direitos Fundamentais Sociais não se deve à falta de leis ordinárias; o problema maior é a não-prestação real dos serviços sociais básicos pelo Poder Público [...] O problema certamente está na formulação, implementação e manutenção das respectivas políticas públicas e

\footnotetext{
${ }^{12}$ Previsto no art. 165 da Constituição Federal de 1988 e regulamentado pelo Decreto 2.829 de 29 de outubro de 1988.

${ }^{13}$ Cf. $\S 2^{\circ}$ do art. 165 da Constituição Federal de 1988.

${ }^{14}$ Visa concretizar os objetivos e metas propostas no Plano Plurianual (PPA), segundo as diretrizes estabelecidas pela Lei de Diretrizes Orçamentárias (LDO).
} 
na composição dos gastos nos orçamentos da União, dos estados e dos municípios (KRELL, 2002, p. 31-32).

A real não-prestação dos serviços sociais de que fala Krell encontra barreiras na chamada "Teoria da Reserva do Possível". Ao se tratar das restrições acerca dos direitos fundamentais, constantemente invoca-se a cláusula da "reserva do possível", mencionada pela primeira vez na Alemanha, na decisão Numerus Clausus promovida pelo Tribunal Constitucional alemão (MÂNICA, 2007, p. 12).

Tal demanda judicial foi proposta por jovens que não tinham sido aprovados nas universidades de medicina de Hamburgo e Munique devido ao limitado número de vagas. A pretensão foi fundamentada no art. 12 da Lei Fundamental da Alemanha, que afirma que todos os alemães têm direito a escolher livremente sua profissão, seu local de trabalho e centro de formação (MÂNICA, 2007, p. 13). Na opinião de Ingo Sarlet, o tribunal alemão entendeu que a prestação reclamada deve corresponder ao que o indivíduo pode razoavelmente exigir da sociedade, de tal sorte que, mesmo em dispondo o estado de recursos e tendo poder de disposição, não se pode falar em uma obrigação de prestar algo que não se mantenha nos limites do razoável (SARLET, 2001, p. 265).

Dessa forma, a efetivação das políticas públicas encontrou seus limites na medida em que ao Estado cumpre a responsabilidade pela justiça social dentro de suas limitações e reservas orçamentárias. Os fatores que aportam à exigibilidade dos direitos sociais são a "reserva do possível" e o "mínimo existencial". A garantia do "mínimo existencial" acaba por constituir o padrão mínimo da efetivação dos direitos sociais de prestação, já que, sem o mínimo necessário à existência, cessa a possibilidade de sobrevivência do indivíduo e, com ela, as condições de liberdade (ROSA, 2005, p. 2525).

Destarte, a discricionariedade do legislador deve se equilibrar nesta gangorra, atentando, de um lado, para o mínimo necessário à existência do ser humano e exigível pela lei, e, de outro, para as reais possiblidades orçamentárias de sua administração. No Brasil, como em outros países periféricos, a questão é justamente analisar quem possui a legitimidade para definir o que seja "o possível” na área das prestações sociais básicas face à composição distorcida dos orçamentos federativos (KRELL, 2002, p. 53).

As necessidades são ilimitadas e os recursos escassos, no entanto, entende Krell que os direitos e garantias dispostos na lei e nos planos de gestão pública devem ser conferidos a todos. Assim, expõe de forma pertinente que: 
(...) se os recursos não são suficientes, deve-se retirá-los de outras áreas (transporte, fomento econômico, serviço de dívida) onde sua aplicação não está tão intimamente ligada aos direitos mais essenciais do homem: sua vida, integridade física e saúde. Um relativismo nessa área pode levar a “ponderações” perigosas e anti-humanistas do tipo 'por que gastar dinheiro com doentes incuráveis ou terminais'? (KRELL, 2002, p. 53).

Dessa forma, os limites impostos pela "reserva do possível", baseados nos estudos de Sarlet, são dados em virtude do limite real de escassez de recursos orçamentários e do valor fundamental da dignidade da pessoa humana. A escassez de recursos orçamentários e a reserva do possível é o que "representaria o verdadeiro limite à restrição dos direitos fundamentais, coibindo eventuais abusos que pudessem levar ao seu esvaziamento ou à sua supressão" (BIGOLIN, 2011, p. 13).

A partir disso, entende-se que a discussão em torno da efetividade dos direitos sociais prestacionais não escapa da análise das condições financeiras do Estado para que os preceitos fundamentais dispostos na Constituição Federal sejam atendidos. No entanto, a escassez de recursos orçamentários jamais poderá se tornar fator impeditivo à garantia das necessidades básicas do ser humano nem que, para isso, seja preciso sacrificar os recursos de áreas menos relevantes. Tudo isso, para que acima de qualquer outra coisa, respeite-se o princípio basilar do constitucionalismo moderno - a dignidade da pessoa humana.

\section{CONSIDERAÇÕES FINAIS}

Os idosos são fruto de sua experiência de vida e, enquanto há vida, existe a possibilidade de aprender, de rever posturas e de conquistar direitos, contribuindo para a melhora da qualidade de vida. Assim, esse trabalho buscou instigar acadêmicos, profissionais e a sociedade em geral a voltarem suas atenções a essa população que se encontra excluída e que vive em condições de vulnerabilidade social.

A Bioética de intervenção permite a análise dos direitos sociais, especificamente daqueles inerentes à pessoa idosa, sob uma ótica mais humanitária, preocupando-se em observar a realidade econômico-sócio-cultural em que a pessoa está inserida. Rompe, dessa maneira, o paradigma da bioética principialista norte-americana, 
que se ocupava com questões relacionadas às ciências médicas e da saúde, alicerçando seus estudos nos quatro princípios-pilares da bioética: autonomia, justiça, nãomaleficência e beneficência.

A análise da concretização dos direitos do idoso através das políticas públicas permite a conclusão de que, apesar destes serem bem amparados pela legislação brasileira atual, ainda há muitas barreiras para que vejam, na prática, suas necessidades sanadas. No entanto, é indiscutível que o surgimento do Estatuto do Idoso, do Plano Nacional do Idoso e dos programas e planos elaborados pela administração pública direcionados ao trato com o idoso, representou um grande avanço na área da saúde, lazer, cultura, transporte, entre outros.

Dessa forma, discutir e refletir sobre o bem estar e a qualidade de vida dos idosos é de grande importância a fim de reconhecer e assegurar direitos e garantias inerentes a estes e também para que surjam novas discussões éticas, proporcionando melhores condições para implementação de medidas de inclusão social de qualidade e equitativamente.

\section{REFERÊNCIAS BIBLIOGRÁFICAS}

BIGOLIN, Giovani. A reserva do possível como limite à eficácia e efetividade dos direitos sociais. Disponível em: <http://www.revistadoutrina.trf4.gov.br/indices/geral0001.htm> Acesso em: 2 mai 2011.

BRUNO. Marta Regina P. Cidadania não tem idade. Serviço Social \& Sociedade. São Paulo: Cortez, ano XXIV, no 75, 2003, p. $74-83$.

BUCCI, Maria P. Dallari. Buscando um conceito de políticas públicas para a concretização dos direitos humanos. Disponível em: <http://www.dhnet.org.br/direitos/textos/politicapublica/index.html>. Acesso em: 2 mai 2011. 
Direito Administrativo e Políticas Públicas. São Paulo:

Saraiva, 2006.

BRASIL. Constituição (1988). Constituição da República Federativa do Brasil: promulgada em 5 de outubro de 1988, com as alterações adotadas pelas Emendas Constitucionais $n^{\text {os }} 1 / 92$ a 56/2007 e pelas Emendas Constitucionais de revisão $n^{\text {os }} 1$ a 64/94. Brasília: Senado Federal, Subsecretaria de Edições Técnicas, 2008. 88p.

BRASIL. Decreto-lei 5296 de 2 de dezembro de 2004, Regulamenta as Leis ${ }^{\circ} 10.048$, de 8 de novembro de 2000, que dá prioridade de atendimento às pessoas que especifica, e 10.098, de 19 de dezembro de 2000, que estabelece normas gerais e critérios básicos para a promoção da acessibilidade. Diário Oficial da República Federativa do Brasil, Brasília, Seção 1, p.5, 03 de dezembro de 2004.

CAMARANO, A. A. et al. Como vive o idoso brasileiro? In: Ana Amélia Camarano [organizadora]. Os novos idosos brasileiros. Muito além dos 60? p. 77-106. Rio de Janeiro, 2004.

CANOTILHO, Joaquim José Gomes. Constituição dirigente e vinculação do legislador. Coimbra: ed. Coimbra, 1982.

DINIZ, Maria Helena. O Estado Atual do Biodireito. $2^{\circ}$ ed. São Paulo: Saraiva, 2002.

DOLL, Johannes. PY, Ligia. O idoso na relação com a morte: aspectos éticos. Qualidade de vida na velhice: enfoque multidisciplinar, Anita Liberalesso Neri [organizadora]. Coleção velhice e sociedade. Campinas, SP: Alínea, 2007. P. 279-300. 
GAMBOA-BERNAL, Gilberto A. Atención domiciliaria de la persona anciana: una perspectiva bioética. Aquichan, 2009, vol. 9. ISSN 1657-5997. Disponível em: <http://redalyc.uaemex.mx/src/inicio/ArtPdfRed.jsp?iCve=74112142006>. Acesso em: 16 jun 2011.

GARRAFA, Volnei. Apresentando a Bioética. Disponível em: <http://www.publicacoesacademicas.uniceub.br/index.php/face/article/viewFile/118/10 2> Acesso em: 2 abr 2011.

Bioética, saúde e cidadania. In: BARCHIFONTAINE, Christian de Paul ; PESSINI, Leo (organizador). Bioética: alguns desafios. $1^{\circ}$ edição, São Paulo: Loyola, 2001.

GARRAFA, Volnei. PORTO, Dora. Intervention bioethics: a proposal for peripheral countries in a context of power and injustice. Bioethics. Vol. 17, p. $399-416$.

GOMES, Sandra Regina. Políticas públicas para a pessoa idosa: marcos legais e regulatórios. Sandra Gomes, Maria Elisa Munhol, Eduardo Dias; [coordenação geral Áurea Eleotério Soares Barroso]. São Paulo: Secretaria Estadual de Assistência e Desenvolvimento Social: Fundação Padre Anchieta, 2009.

GONÇALVES, Evelise Ribeiro. O olhar da Bioética de Intervenção no trabalho do cirurgião-dentista do Programa Saúde da Família (PSF). Revista Bioética, vol. 18, nº 1 , 225-239, 2010. Disponível em: <http://revistabioetica.cfm.org.br/index.php/revista_bioetica/issue/view/35> Acesso em: 2 jun 2011. 
GONÇALVES, Leonardo Augusto. O Ministério Público e a busca pela inclusão social. Atuação no âmbito das políticas públicas. Jus Navigandi, Teresina, ano 15, n. 2482, 18 abr. 2010. Disponível em: <http://jus.com.br/revista/texto/14579>. Acesso em: 7 mai 2011.

GUIMARÃES, M. P. Acessibilidade ambiental para todos na escala qualitativa da cidade. In: TOPOS - Revista de Arquitetura e Urbanismo, Vol. 1, Belo Horizonte: NPGAU, 1999.

IBGE, Censo 2010. Fundação Instituto Brasileiro de Geografia e Estatística, dados referentes à população do Brasil. Disponível em: <http://www.ibge.gov.br/home/> Acesso em: 26 abr 2011.

KRELL, Andreas J. Direitos sociais e controle judicial no Brasil e na Alemanha: os (des)caminhos de um direito constitucional comparado. Porto Alegre: Sergio Antonio Fabris Editor, 2002.

LENZA, Pedro. Direito Constitucional Esquematizado. $14^{\circ}$ ed. rev. atual. e ampl. São Paulo: Saraiva, 2010. 1024 p.

MÂNICA, Fernando Borges. Teoria da Reserva do Possível: Direitos Fundamentais a Prestações e a Intervenção do Poder Judiciário na Implementação de Políticas Públicas. Revista Brasileira de Direito Público, Belo Horizonte, ano 5, n. 18, p. 169-186, jul./set. 2007.

MARINELA, Fernanda. Direito Administrativo. $4^{\circ}$ ed. ver. atul. e ampl. Niterói, RJ: Impetus, 2010. 1072 p. 
OLIVEIRA, Régis Fernandes de. Curso de Direito Financeiro. São Paulo: RT, 2006.

OMS. Organização Mundial da Saúde, CIF: Classificação Internacional de Funcionalidade, Incapacidade e Saúde. [Centro Colaborador da Organização Mundial da Saúde para a Família de Classificações Internacionais, org.; coordenação da tradução Cassia Maria Buchalla]. São Paulo: Editora da Universidade de São Paulo - EDUSP; 2003.

PASCHOAL, S. M. P. Autonomia e independência. In: Netto, M. P. (org). Gerontologia. São Paulo: Atheneu, 1996. P. 313-323.

PERRACINI, Monica Rodrigues. PRADO, Adriana Romeiro de Almeida. A construção de Ambientes favoráveis aos idosos. Qualidade de vida na velhice: enfoque multidisciplinar. Anita Liberalesso Neri [organizadora]. Coleção velhice e sociedade. Campinas, SP: Alínea, 2007. P. 221-229.

ROSA, Marizélia Peglow. A concretização dos direitos humanos sociais e a reserva do possível. In: XVII Encontro Preparatório para o Congresso Nacional - CONPEDI, 2008, Salvador. Disponível em: <http://www.conpedi.org.br/conteudo.php?id=2> Acesso em: 29 abr 2011.

SARLET, Ingo Wolfgang. A eficácia dos direitos fundamentais. 2 ed. Porto Alegre: Livraria do Advogado, 2001.

UNESCO. Declaração Universal sobre Bioética e Direitos Humanos. [online]. Paris, 19 out 2005. Tradução brasileira sob a responsabilidade da Cátedra Unesco de Bioética da 
Universidade de Brasília. Disponível em: <www.sbbioetica.org.br>. Acesso em: 20 mai 2011.

VERA, R. P. País Jovem com cabelos brancos: a saúde do idoso no Brasil. Rio de Janeiro: Relume Dumará/UERJ, 1994. 